\title{
Trade and Economic Growth in Developing Countries: Evidence from sub-Saharan Africa
}

\author{
Zhang Xuefeng \\ School of Economics and Management \\ North China University of Technology \\ Beijing, China \\ E-mail: zxf511@163.com \\ Wei Zhifeng \\ Beijing SGITG-Accenture Information Technology \\ Co.,LtdBeijing, China
}

\author{
Liu Yongqing \\ State Grid Information \& Telecommunication Group \\ Co.,Ltd \\ Beijing, China \\ LiseB \\ School of Economics and Management \\ North China University of Technology \\ Beijing, China
}

\begin{abstract}
This study investigates how trade openness affects economic growth in developing countries, with a focus on subSaharan Africa (SSA). We use a dynamic growth model with data from 42 SSA countries covering 1980 to 2012. We take the Pooled Mean Group estimation technique, which is suitable for drawing conclusions from dynamic heterogeneous panels by considering long-run equilibrium relations. The empirical evidence indicates that there is a trade threshold below which greater trade openness has beneficial effects on economic growth and above which the trade effect on growth declines. The evidence also indicates an inverted $U$-curve (Laffer Curve of Trade) response that is robust to changes in trade openness measures and to alternative model specifications, suggesting the non-fragility of the linkage between economic growth and trade openness in sub-Saharan countries. Our findings are promising and support the view that the relation between trade openness and economic growth is not linear for SSA. Accordingly, SSA countries must have more effective trade openness, particularly by productively controlling import levels, so as to boost their economic growth through international trade.
\end{abstract} Africa

Keyword-Trade openness; Economic growth; Sub-Saharan

\section{INTRODUCTION}

Trade liberalization has become widespread over the past three decades, particularly among developing and transition economies, as a result of the perceived limitation of import substitution-based development strategies and the influence of international financial institutions, such as the International Monetary Fund and the World Bank, which have often made their support conditional on trade liberalization. The fundamental rationale for this degree of commitment to a program of trade reform is the obvious belief that liberalization is a prerequisite to a transition from relatively closed to relatively open economies. Economists generally agree that open economies grow faster than their counterparts do. If openness is indeed positively related to growth, it then follows that liberalization is a requirement for growth. Despite their early promise, recent experience suggests that not all trade reforms have been as successful as anticipated[1].

Supported by the North China University of Technology "The belt and

Road" countries talent training base project and Beijing Municipal

Commission of Education fundamental research funds (Grant

No.110052971803-056)
The relationship between trade openness and economic growth has been theoretically controversial. While conventional wisdom predicts a growth-enhancing effect of trade, recent developments suggest that trade openness is not always beneficial to economic growth. Increased international trade can generate economic growth by facilitating the diffusion of knowledge and technology from the direct import of high-tech goods. Trade facilitates integration with the sources of innovation and enhances gains from foreign direct investment. By increasing the size of the market, trade openness allows economies to better capture the potential benefits of increasing returns to scale and economies of specialization. However, endogenous growth models postulate that the contribution of trade to economic growth varies depending on whether the force of comparative advantage orientates the economy's resources toward activities that generate long-run growth or away from such activities. Moreover, theories suggest that, due to technological or financial constraints, less-developed countries may lack the social capability required to adopt technologies developed in more advanced economies. Thus, the growth effect of trade may differ according to the level of economic development. Despite its potential positive effect on growth, some theoretical studies claim that trade openness may hamper growth. The empirical analyses are as inconclusive as the theoretical perspectives. Some studies have identified a positive association between trade openness and economic growth, while others have found no association, or even a negative association[2]. The literature is inconclusive partly because different analysts use different proxies for liberalization or trade openness and rely on different methodologies. The evidence for growth enhancements through trade liberalization displays mixed effects because of problems with misspecification and the diversity among the liberalization indices used.

Using cross-country data and initial real income per capita as the threshold variable, Kim and Lin found significant threshold effects in the relationship between trade and growth. Greater openness to international trade has positive impacts on economic growth for high-income economies. For low-income 
economies, however, higher trade openness has negative impacts on economic growth. The beneficial effects of trade liberalization thus seem to increase as economies develop, confirming the arguments about the adoptive capacity of a country in determining knowledge accumulation and technology implementation.

This study contributes to research by assessing whether the relationship between trade and growth differs between more open and less open countries in SSA. This distinction is important, as various theoretical models and empirical results have suggested that the effect of trade on economic growth may vary according to the level of trade openness and level of income as a measure of economic development. Particularly for developing countries, the lack of investment in human capital and of a well-functioning financial system may hamper the growth expected from trade liberalization through technological innovation. For such countries, Kim and Lin suggest selective protection. If such a nonlinear relationship exists, we should be able to estimate the threshold at which the sign of the relation between trade and growth switches. This study reexamines the role of trade and contributes to the literature by empirically analyzing the threshold effects of trade on economic growth based on panel data for sub-Saharan African countries. The empirical evidence is based on a dynamic growth model using data from 42 sub-Saharan countries covering 1980 to 2012. We employ the Pooled Mean Group estimation technique, which is appropriate for drawing conclusions from dynamic heterogeneous panels by considering long-run equilibrium relations. Our findings support the view that the relation between trade globalization and economic growth is not linear for sub-Saharan Africa and point to an inverted $U$ curve-type response.

\section{DATA AND VARIABLE DEFINITIONS}

\section{A. Trade openness variables}

Following Le Goff and Singh[5] and Ulaşan [6], we chose as our trade openness variable a measure of effective trade openness and not a measure of liberalization policies because the main concern of this study is the impact of actual globalization on economic growth. We employ three variables for trade openness: we use the sum of exports and imports as a share of GDP (TRADE); for a robustness check, we also consider exports (EXPORT) and imports (IMPORT) as a share of GDP separately.

\section{B. Control variables}

Since macroeconomic policies affect growth performance through their impact on the rate of inflation, financial development, the financial crisis, external debt, investment in human and physical capital, and institutional quality, variables for these effects are used in the growth equation to capture the impacts of such policies. The effect of inflation (INF) is a controversial issue. Some studies claim that inflation has a positive impact on growth, while other studies suggest that this effect is characterized by a nonlinear relationship. Inflation is the rate of change in price levels. Investment (INV) has been used in empirical studies because it is viewed as a direct proxy of contribution to capital accumulation, as well as an indicator of efforts to develop basic economic infrastructure. It is measured in this study as gross fixed capital formation. Human capital is a key determinant of technology adoption as permitted by trade openness. The effect of human capital is captured by using two variables: the gross secondary enrollment rate (EDU) and the population growth rate (POP). The lack of a well-functioning financial system may prevent less-developed countries from taking full advantage of technology transfer from trade openness and may impact economic growth. Financial development $(F D)$ is measured by private credit as a share of GDP. Institutional quality is included in the growth equation to capture the impact of political rights and civil liberties. It is hypothesized that the absence of political rights and civil liberties lowers the security of life and property, thus reducing the rate of accumulation and the efficiency of factor of production. Institutional quality therefore impacts economic growth and may also impact trade openness [3].

The PMG estimation results are summarized in Tables 1 to 3 . We present only the long-run coefficients for the analysis (short-run coefficients are available on request). The short-run error correction term (speed of adjustment) is significantly negative for all models, confirming the co-integration relationship between the variables of interest and implying that the linkage between economic growth and the explanatory variables is characterized by high predictability and that the spread movement is mean-reverting. 
TABLE I PMG LONG-RUN ESTIMATES OF IMPACT OF TRADE OPENNESS ((X + M)/GDP)) ON GROWTH OF PER CAPITA GDP, $1980-2012$.

\begin{tabular}{|c|c|c|c|c|}
\hline & Model 1 & Model 2 & Model 3 & Model 4 \\
\hline GDP(-1) & Coef. & Coef. & Coef. & Coef. \\
\hline LINV & $-0.0686^{* * *}$ & $-0.0759^{* * *}$ & $-0.0334^{* * *}$ & $-0.0968^{* * *}$ \\
\hline LFD & $0.4168^{* * *}$ & $0.4430^{* * *}$ & $0.5529^{* * *}$ & $0.2014^{* * *}$ \\
\hline INF & $-0.1425^{* * *}$ & $-0.1227^{* * *}$ & $2.1508^{* * *}$ & $-0.1360^{* * *}$ \\
\hline IGOV & $-0.0001^{* * *}$ & $-0.0001^{* * *}$ & $-0.0004^{* * *}$ & $-0.0003^{* *}$ \\
\hline POP & $0.2424^{* * *}$ & $-1.0389^{* * *}$ & $0.1398^{* *}$ & $-0.0815^{* * *}$ \\
\hline EDU & $-0.0317^{*}$ & $-0.0299^{* *}$ & $0.1135^{* * *}$ & $-0.0213^{* * *}$ \\
\hline CRISIS & $0.0079^{* * *}$ & $0.0074^{* * *}$ & $0.0083^{* * *}$ & $-0.0229^{* * *}$ \\
\hline LDEBT & $-0.1063^{* * *}$ & $-0.1211^{* * *}$ & $-0.1302^{* *}$ & 0.0171 \\
\hline LTRADE & $-0.0380^{* *}$ & $-0.0585^{* * *}$ & -0.0119 & $-0.1112^{* * *}$ \\
\hline LTRADE2 & $1.9357^{* * *}$ & $0.3480^{* * *}$ & $1.4348^{* * *}$ & 0.0084 \\
\hline IGOV*LTRADE & $-0.1975^{* * *}$ & & & 1302 \\
\hline LFD*LTRADE & & $0.2918^{* * *}$ & & \\
\hline EDU*LTRADE & & & $-0.6004^{* * *}$ & \\
\hline Cons & & & & $0.0094^{* * *}$ \\
\hline Number of countries & 42 & 42 & 42 & $0.3521^{* * *}$ \\
\hline Number of observations & 1302 & 1302 & 1302 & 42 \\
\hline
\end{tabular}

The estimation results indicate a nonlinear relationship between trade openness and economic growth, and the evidence is robust to alternative trade openness measures (i.e., sum of exports and imports as a share of GDP and exports and imports as a share of GDP separately). The results show the presence of a Laffer Curve of trade (inverted U) and confirm that trade openness has a positive and significant effect on economic growth but only up to a threshold; above this threshold, the effect declines. These results indicate that the openness variables are relevant drivers of economic growth for sub-Saharan countries over the long run but that openness should be controlled since the associated coefficients of such variables and their quadratic terms are (respectively) positively and negatively significant at conventional levels.

For the first measure of trade openness (sum of exports and imports as a share of GDP), the threshold is estimated to be $134.21 \%$. In other words, trade is associated with higher levels of economic growth up to the threshold where the sum of exports and imports represents $134.21 \%$ of GDP. Beyond this threshold, the effect of trade on growth declines. According to the second measure of trade openness (exports as a share of GDP), the findings indicate a threshold of $355.68 \%$, suggesting that trade affects economic growth positively until exports account for $355.68 \%$ of GDP. After this threshold, trade's impact on economic growth declines. For the third measure (imports as share of GDP), trade is associated with a higher level of growth when imports account for $33.16 \%$ of GDP; the effect declines after this threshold (see Table A3 of Appendix 1). The probability of reaching these threshold proportions of trade (134.21\% or $355.68 \%$ of GDP) is small, practically non-existent, indicating that openness to exports may not reduce economic growth for sub-Saharan African countries. For the third measure, the result suggests that imports can reduce economic growth. Thus, sub-Saharan African countries must efficiently control trade openness, particularly import levels, when seeking to boost their economic growth through international trade. Trade provides developing countries with access to the investment and intermediate goods that are vital to their development and the transfer of foreign technology, but such countries should productively reduce the import of consumption goods, by creating an environment that is conducive to efficiently producing domestically competing products in which there is dynamic comparative advantage. 
These findings suggest that the openness of African economies to international trade should be associated with growth, which is in line with other empirical works [4]. Unlike in previous studies, however, the relation is not linear, confirming the fragility of the links between trade openness and economic growth for sub-Saharan African countries. This result is in line with the findings on Organization for Economic Cooperation and Development (OECD) and nonOECD countries.

While the first regression considers only trade openness effects, we then examine the influence of several structural country characteristics in the trade-growth relationship. The results with the interaction terms are shown in Models 2, 3, and 4 . We first test whether the trade-growth relationship changes with the development of the financial sector (Model $3)$. The coefficient of the interaction term with financial development is negative and significant for the first and third measures of trade openness and is positive for the second measure. These results suggest that a greater openness to trade via exports is associated with strong economic growth when the financial sector is more developed. In other words, easier access to credit may allow the export-oriented sectors to benefit more from trade openness. However, greater openness via imports is associated with lower economic growth, suggesting that easier access to credit among import-oriented sectors may reduce economic growth.

Model 4 shows the results of the estimations testing the role of human capital in the trade-growth relationship. The beneficial impact of an increase in trade openness on growth is greater when investment in human capital is higher. We find that an increase in the gross secondary enrollment rate is associated with a higher growth rate. This result is consistent with theoretical models suggesting that the effect of trade on growth may depend on the adoption of technology determined by human capital. Finally, we examine whether the relationship between openness to trade and economic growth may hinge on a country's institutional environment (Model 2). The results suggest that trade openness may be favorable to economic growth when institutional quality improves. In others words, an environment with high-quality governance seems to be more favorable to the emergence of new enterprises, allowing the economy to grow faster.

\section{CONCLUSION}

(1)In this study, we have tested a dynamic growth model for sub-Saharan African economies using three measures of trade openness. Our results suggest that trade openness may impact growth favorably in the long run, but the effect is not linear. Our results show the presence of a Laffer Trade Curve (inverted $\mathrm{U}$ ) and confirm that trade openness has a positive and significant effect on economic growth only up to a threshold, above which the effect declines. These results are robust to changes in trade openness measures.

(2)The non-linear relation between trade openness and economic growth suggests that the benefits of trade are not automatic. The growth effects of trade openness may differ according to the level of trade openness. Accordingly, subSaharan African countries must productively control trade openness, particularly the import of consumption goods, in boosting their economic growth through international trade.

(3)Our results suggest that trade openness must be accompanied by complementary policies aimed at encouraging the financing of new investment and enhancing the quality of institutions and the ability to adjust and learn new skills. These policies would then allow resources to be reallocated away from less productive activities and toward more promising ones. Trade globalization should therefore not be seen in isolation. Additional policies are needed to enhance its impact on economic growth. Sub-Saharan countries should carry out relevant policy reform to encourage investment, allow effective governance, and promote human capital accumulation.

\section{REFERENCE}

[1] T. Singh, Does international trade cause economic growth? A survey World Econ., 33 (11) (2010), pp: 1517-1564.

[2] J.W. Musila, Z. Yiheyis, The impact of trade openness on growth: the case of KenyaJ. Policy Model., 37 (2015) (2015), pp: 342-354.

[3] D. Acemoglu, J.A. Robinson, Why Nations Fail: The Origins of Power, Prosperity, and Poverty Crown Publisers, Crown Publishing Group, a Division of Random House (2012), pp: 1-571.

[4] M.E. Erçakar, Growth, foreign direct investment, trade and inflation: an empirical application on Turkey Middle East. Finance Econ., 9 (2011), pp: 137-147.

[5] M. Le Goff, R.J. Singh, Does trade reduce poverty? A view of Africa J. Afr. Trade, 1 (2014) (2014), pp: 5-14.

[6] B. Ulaşan, Trade openness and economic growth: panel evidence Appl. Econ. Lett., 22 (2) (2015), pp: 163-167. 